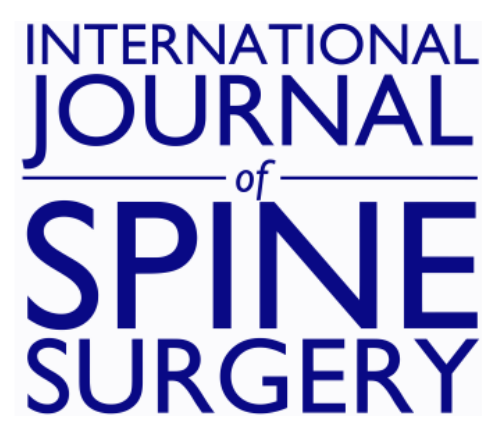

\title{
Chronic Atlantoaxial Rotatory Subluxation in an Adult Following a Traumatic Event: A Case Report
}

CAMERON KIA, SCOTT MALLOZZI and ISAAC MOSS

Int J Spine Surg 2020, 14 (4) 488-492

doi: https://doi.org/10.14444/7064

http://ijssurgery.com/content/14/4/488

This information is current as of April 26, 2023.

Email Alerts Receive free email-alerts when new articles cite this article. Sign up at:

http://ijssurgery.com/alerts 


\title{
Chronic Atlantoaxial Rotatory Subluxation in an Adult Following a Traumatic Event: A Case Report
}

\author{
CAMERON KIA, MD, SCOTT MALLOZZI, MD, ISAAC MOSS, MD \\ University of Connecticut Health Center, Farmington, Connecticut
}

\begin{abstract}
Background: Traumatic rotatory subluxation of the atlantoaxial joint is a rare but potentially life-threatening injury in adults. While acute cases have been shown to be managed successfully with closed reduction, chronic injuries in skeletally mature patients have rarely been reported.

Methods: We present management of a 64-year-old female who presents 2.5 years after a traumatic cervical injury with neck pain and torticollis. Imaging revealed rotatory subluxation of $\mathrm{C} 1-\mathrm{C} 2$ without cord impingement. A focused appraisal of the reported literature was also performed.

Results: Successful reduction was achieved with halo cervical traction, followed by definitive treatment with atlantoaxial arthrodesis.

Conclusions: Cases of fixed, chronic $\mathrm{C} 1-\mathrm{C} 2$ rotatory subluxation after traumatic etiology may be amenable to closed reduction with skeletal traction and fusion.

Level of Evidence: 4.

Clinical Relevance: Chronic, post-traumatic atlantoaxial rotatory subluxation in the adult population is extremely rare, without a well-described treatment algorithm. The purpose of this case report is to highlight the reduction and fixation of someone with this injury.
\end{abstract}

Cervical Spine

Keywords: rotatory subluxation, C1-C2 fusion, atlantoaxial joint

\section{INTRODUCTION}

The atlantoaxial joint and its concomitant ligaments provide significant rotational and biomechanical stability to the cervical spine. ${ }^{1}$ Isolated traumatic rotatory subluxation of the atlantoaxial joint without fracture is a rare injury, ${ }^{1-3}$ with no consensus for management in the adult population. ${ }^{4}$ Missed or neglected treatment of these injuries may lead to a chronic rotated neck posture (mimicking torticollis), pain, and potential for neurologic compromise. ${ }^{4-6}$ While acute traumatic atlantoaxial instability may be treated with closed management, ${ }^{1}$ delayed presentation can limit reducibility, maintenance of reduction, or both..$^{7-11}$

Chronic atlantoaxial rotatory subluxation (AARS) has been reported in the pediatric population, with several authors recommending attempted treatment with external halo bracing if reducible. ${ }^{12,13}$ However, the etiology in children is most often secondary to infection rather than direct trauma. Due to the rarity of this traumatic event, subluxations can often be missed on standard radiographs in the acute setting. ${ }^{14}$
The associated spasm and contracture of the sternocleidomastoid that occurs with a late presentation ${ }^{4}$ may require open reduction and arthrodesis of the atlantoaxial joint.

To the authors' knowledge, delayed presentation ( $>2$ years) of purely traumatic atlantoaxial subluxation in the skeletally mature individual has not been reported. The purpose of the present report was to present a rare case of chronic AARS after a trauma in an adult patient treated successfully with closed reduction and arthrodesis.

\section{Case Report}

An otherwise healthy 64-year-old female presented to the clinic after sustaining a ground level fall, hitting the right side of her neck on a lower cabinet 2.5 years before. She reported complaints of neck pain, difficulty with neck range of motion, along with an inability to comfortably face her head directly forward. The patient denied any numbness, weakness, or changes in balance and coordination. Over the course of 2 years, the patient attempted conservative treatment with physical therapy, acu- 


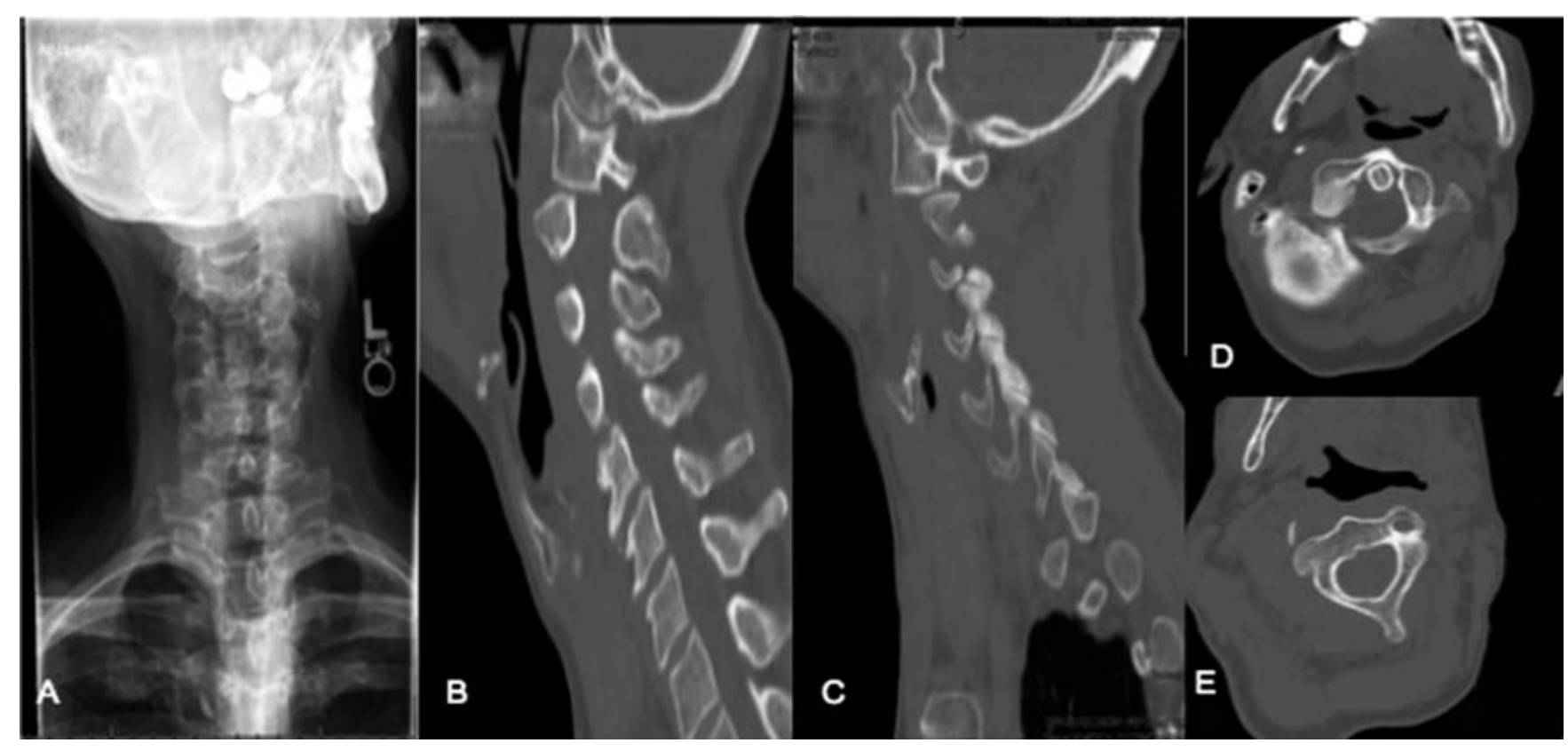

Figure 1. (A) Demonstrates radiographic rotation of the head in the anterior-posterior view. Computed tomography scan showed (B) posterior and (C) anterior subluxation of the $\mathrm{C} 1$ lateral mass in relation to the $\mathrm{C} 2$ facet. Axial view demonstrated $(\mathrm{D})$ the $\mathrm{C} 1$ arch rotated about odontoid, significantly subluxed compared to (E) the $\mathrm{C} 2$ vertebrae.

puncture, muscle relaxants, and multiple Botox injections.

\section{Physical Exam and Imaging}

On physical exam, the patient was neurologically intact. The patient's head was fixed in a position rotated to the left, with limited ability to rotate $(\sim 20 \%)$ to the right side. In addition, the patient was unable to fully flex or extend the neck. Standard cervical spine $\mathrm{x}$-rays including flexion/extension radiographs were obtained, demonstrating no evidence of fracture or frank dislocation. Computed tomography (CT) obtained demonstrated rotary displacement of the atlas without anterior displacement (Fielding type 1, Figure 1) in relation to the odontoid. Magnetic resonance imaging was also performed with no evidence of cord compression.

\section{Treatment Management}

The decision was made to admit the patient to the hospital, with an initial attempt at closed reduction. A halo crown was secured, and $10 \mathrm{lb}$ of in-line traction was initially placed (Figure 2A). Over the course of 24 hours, an additional $10 \mathrm{lb}$ were added. Repeat radiographs after approximately 30 hours in traction demonstrated adequate reduction of the subluxation (Figure 2C). Given the chronicity of the injury, it was felt that the chance of recurrent subluxation would be high, so the patient was taken to the operating room for $\mathrm{C} 1-\mathrm{C} 2$ posterior spinal fusion. After a total of 48 hours of halo traction, the patient was brought to the operating room with the halo attached to a Mayfield head positioner on a rotating Jackson table. Intraoperative three-dimensional (3D) fluoroscopy was then used to confirm that reduction was still maintained before hardware placement (Figure 3). Using C1 lateral mass and C2 pedicle screws via the technique described by Harms et $a l,{ }^{15}$ the atlantoaxial joint was fixed in anatomic alignment, with demineralized bone matrix putty used to augment the arthrodesis (Figure 4). The patient tolerated the procedure well without complication. She was discharged on postoperative day 2 in a hard collar with good maintenance of reduction.

\section{DISCUSSION}

Chronic subluxation of the atlantoaxial joint is a rare traumatic event in adults, with no current consensus for management. We present a case describing a patient who presented 2.5 years from injury with torticollis that was reducible using halo traction followed by posterior $\mathrm{C} 1-\mathrm{C} 2$ fusion.

The atlantoaxial joint is formed by 2 saddleshaped, biconvex surfaces that contribute to roughly $50 \%$ of axial neck rotation. ${ }^{3,16}$ In addition, the transverse and alar ligaments are important static stabilizers, preventing anterior translation of $\mathrm{C} 1$ on 


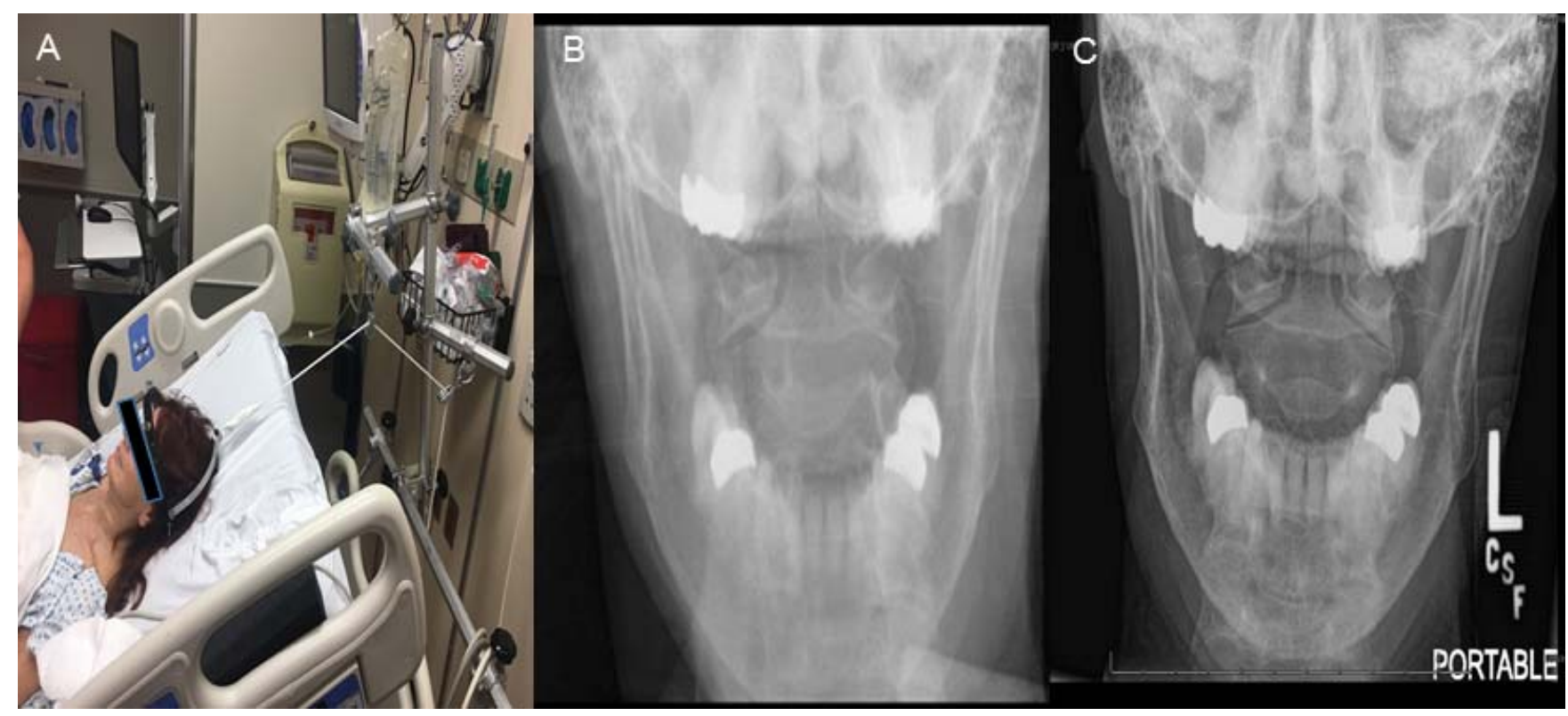

Figure 2. (A) Closed reduction using in line halo traction was applied. (B) Pretraction open-mouth odontoid view demonstrated bilateral asymmetry of the C1-C2 facet joints. (C) Significantly improved reduction of the atlantoaxial subluxation was seen following in line traction.

the C2 vertebrae. ${ }^{1}$ Authors of previous cadaveric studies simulating rotatory subluxation or dislocation have suggested that facet joint disruption followed by the alar ligaments may be the mechanism by which these injuries occur. ${ }^{17,18}$ AARS without associated fracture is rare in adults, with most cases in the literature describing either unilateral or bilateral facet dislocation. ${ }^{19-21}$ The cause of this dislocation has been generally due to higher energy trauma, such as a fall from height, motor vehicle accidents, or sports-related injuries. $^{17,22}$

Despite the rarity of this injury, the Fielding classification was developed to describe 4 types of rotatory instability. ${ }^{23}$ Type 1 , as seen in this case, is



Figure 3. (A) Intraoperative positioning in Mayfield positioner with bilateral bite blocks to allow for open-mouth odontoid view during surgery. (B) A threedimensional C-arm scan demonstrated maintained reduction before instrumentation. rotatory subluxation without disruption of the atlantodens interval. With disruption of the transverse ligament, progressive changes in the atlantodens interval (type 2) can occur, with potential impingement on the spinal cord in types 3 or 4 after facet dislocation. While this classification helps with communication of the injury, it does not provide guidance for treatment or recurrence. Singh et $\mathrm{al}^{24}$ reported a case of a 25-year-old female with traumatic bilateral facet rotatory subluxation mimicking torticollis after a motor vehicle collision. Although initially missed on radiographs, the patient was treated acutely with a halo brace for 4 weeks, with resolution of symptoms and maintenance of reduction at 1 year. ${ }^{24}$ Venkatesan et $\mathrm{al}^{1}$ reported 2 similar cases of traumatic AARS in

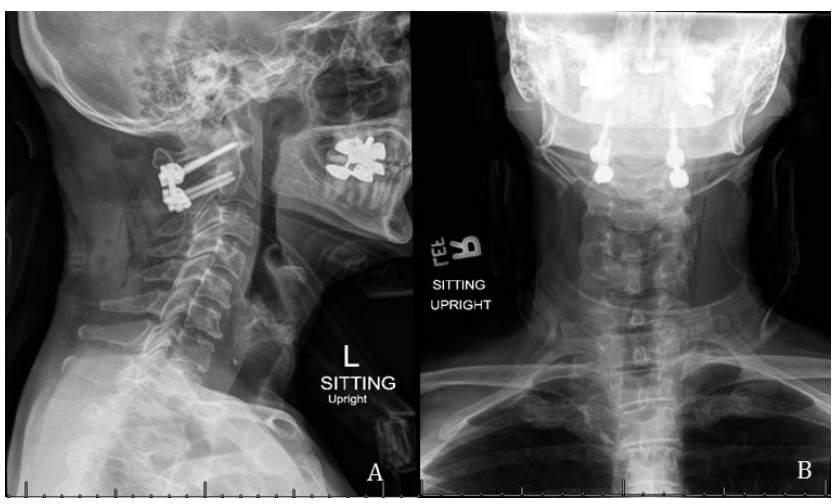

Figure 4. (A) Postoperative $\mathrm{C} 1-\mathrm{C} 2$ instrumented posterior spinal fusion with (B) correction of preoperative clinical torticollis seen on the anterior-posterior view. 
skeletally mature patients after motor vehicle accidents. Both patients underwent acute reduction with halo traction, followed by 8 weeks in a hard collar. ${ }^{1}$ The patients maintained anatomic reduction at over 2-year follow up, without requiring arthrodesis. ${ }^{1}$ While these reports showed success without surgical intervention in cases of acute AARS, treatment of chronic cases of subluxation in adults have not established.

Chronic AARS has previously been defined as subluxation of greater than 3 months. ${ }^{3,22}$ Ishii et al ${ }^{4}$ recently reported a case series of 12 consecutive pediatric patients with chronic atlantoaxial instability. The authors recommended a "remodeling therapy" involving initial closed reduction in the operating room followed by halo bracing for up to 3 months to allow for the $\mathrm{C} 2$ facet to remodel. ${ }^{4,25}$ Although only 3 patients in their cohort were secondary to trauma, no patient had recurrence of symptoms nor subluxation at a mean follow up of 42 months. ${ }^{4}$ The authors recommended fusion for patients that are either irreducible or have bony union between $\mathrm{C} 1$ and $\mathrm{C} 2$. Pang et $\mathrm{al}^{12}$ examined risk factors for recurrence after closed reduction and found that Fielding type 1 and chronic subluxations yielded the highest risk of recurrence $(75 \%$ and $80 \%$, respectively). Given the chronicity of injury in the patient presented, we felt management in a neck orthosis alone would result in a high risk of recurrence. Interestingly, we found the patient's subluxation was still amenable to closed reduction in halo traction, limiting the need for significant open reduction maneuvers prior to fusion.

Several fixation options have been proposed for atlanatoaxial arthrodesis. ${ }^{26}$ Wire fusion was originally proposed; however, pseudoarthrosis and construct failure have been reported. ${ }^{27-29}$ Transarticular screw fixation has also been used but is technically demanding and may not be suitable in cases of aberrant vertebral artery anatomy. ${ }^{30}$ For this reason, obtaining a CT angiogram is essential in preoperative planning. The current authors used a Harms technique with polyaxial screws in the $\mathrm{C} 1$ lateral masses and $\mathrm{C} 2$ pedicles. This technique has shown several advantages over transarticular, such as a more superior and medial screw trajectory to reduce risk to the vertebral artery. ${ }^{30,31}$ In addition, it has been shown to be biomechanically stronger than transarticular fixation. With regard to intraoperative imaging, 3D fluoroscopy can be helpful to confirm reduction and screw placement. If this is unavailable, the authors recommend the use of tall bite blocks placed along the edges of the mouth bilaterally to allow for intraoperative open-mouth odontoid views.

Posttraumatic atlantoaxial rotatory stability is a rare injury but can be missed on standard radiographs. Adults who present with torticollis after a trauma should obtain a CT scan to examine for $\mathrm{C} 1-$ $\mathrm{C} 2$ subluxation or dislocation. Closed reduction should be attempted; however, the chronicity of the injury may place it at high risk of recurrence if arthrodesis is not performed.

\section{REFERENCES}

1. Venkatesan M, Bjatt R, Newey ML. Traumatic atlantoaxial rotatory subluxation (TAARS) in adults: a report of two cases and literature. Injury. 2012;43(7):1212-1215.

2. Moore KR, Frank EH. Traumatic atlantoaxial rotatory subluxation and dislocation. Spine. 1995;20(17):1928-1930.

3. Wortzman G, Dewar FP. Rotatory fixation of the atlantoaxial joint: rotatory atlantoaxial subluxation. Radiology. 1968;90(3):479-487.

4. Ishii K, Toyama Y, Nakamura M, Chiba K, Matsumoto M. Management of chronic atlantoaxial rotatory fixation. Spine. 2012;37(5):278-285.

5. Hawi N, Alfke D, Liodakis E, et al. Case report of a traumatic atlantoaxial rotatory subluxation with bilateral locked cervical facets: management, treatment, and outcome. Case Rep Orthop. 2016;2016:7308653.

6. Jeon SW, Jeong JH, Moon SM, Choi SK. Atlantoaxial rotatory fixation in adults patient. J Korean Neurosurg Soc. 2009;45(4):246-248.

7. Phillips WA, Hensinger RN. The management of rotatory atlanto-axial subluxation in children. J Bone Joint Surg Am. 1989;71(5):664-668.

8. Subach BR, McLaughlin MR, Albright AL, et al. Current management of pediatric atlantoaxial rotatory subluxation. Spine. 1998;23(20):2174-2179.

9. Crossman JE, David K, Hayward R, et al. Open reduction of pediatric atlantoaxial rotatory fixation: long-term outcome study with functional measurements. $J$ Neurosurg. 2004;100(3):235-240.

10. Ishii K, Chiba K, Maruiwa $\mathrm{H}$, et al. Pathognomonic radiological signs for predicting prognosis in patients with chronic atlantoaxial rotatory fixation. $J$ Neurosurg Spine. 2006;5(5):385-391.

11. Crossman JE, Thompson D, Hayward RD, et al. Recurrent atlantoaxial rotatory fixation in children: a rare complication of a rare condition. Report of four cases. $J$ Neurosurg. 2004;100(3):307-311.

12. Pang D, Li V. Atlantoaxial rotatory fixation. Part 3-a prospective study of the clinical manifestation, diagnosis, management, and outcome of children with alantoaxial rotatory fixation. Neurosurgery. 2005;57(5):954-972.

13. Phillips WA, Hensinger RN. The management of rotatory atlanto-axial subluxation in children. $J$ Bone Joint Surg Am. 1989;71(5):664-668.

14. Maile S, Slongo T. Atlantoaxial rotatory subluxation: 
realignment and discharge within 48 h. Eur J Emerg Med. 2007;14(3):167-169.

15. Harms J, Melcher RP. Posterior C1-C2 fusion with polyaxial screw and rod fixation. Spine. 2001;26(22):2467-2471.

16. Grisel P. Enucleation de l'atlas et torticollis nasopharyngien. Presse Med. 1930;38:50-53.

17. Robertson PA, Swan HAP. Traumatic bilateral rotatory facet dislocation of the atlas on the axis. Spine. 1992;17(10):12521254.

18. Willauschus WG, Kladny B, Beyer WF, Gluckert K, Arnold H, Scheithauer R. Lesions of the alar ligaments, in vivo and in vitro studies with magnetic resonance imaging. Spine. 1995;20(23):2493-2498.

19. Wong DA, Mack RP, Craigmile TK. Traumatic atlantoaxial dislocation without fracture of odontoid. Spine. 1991;16(5):587-589.

20. Patzakis MJ, Knopf A, Elfering M, Hoffer M, Harvey JP Jr. Posterior dislocation of the atlas on the axis; a case report. $J$ Bone Joint Surg Am. 1974;56(6):1260-1262.

21. Sassard WR, Heinig CF, Pitts WR. Posterior atlantoaxial dislocation without fracture. Case report with successful conservative treatment. J Bone Joint Surg Am. 1974;56(3):625628.

22. Corner EM. Rotatory dislocations of the axis. Ann Surg. 1907;45:9-26.

23. Fielding JW, Hawkins RJ. Atlanto-axial rotatory fixation (fixed rotatory subluxation of the atlanto-axial joint). J Bone Joint Surg Am. 1977;59(1):37-44.

24. Singh VK, Singh PK, Balakrishnan SK, Leitao J. Traumatic bilateral atlantoaxial rotatory subluxation mimicking as torticollis in an adult female. J Clinic Neuroscience. 2009; 16(5):721-722.

25. Ishii K, Matsumoto M, Momoshima S, et al. Remodeling of $\mathrm{C} 2$ facet deformity prevents recurrent subluxation in patients with chronic atlantoaxial rotatory fixation (AARF) - a novel strategy for treatment of chronic AARF. Spine. 2010;36(4):E256-E262.

26. Sim HB, Lee JW, Park JT, Mindea SA, Lim J, Park J.
Biomechanical evaluations of various $\mathrm{C} 1-\mathrm{C} 2$ posterior fixation techniques. Spine. 2011;36(6):401-407.

27. Coyne TJ, Fehlings MG, Wallace MC, et al. C1-C2 posterior cervical fusion: long-term evaluation of results and efficacy. Neurosurgery. 1995;37(4):688-692; discussion 692-693.

28. Papagelopoulos PJ, Currier BL, Hokari Y, et al. Biomechanical comparison of $\mathrm{C} 1-\mathrm{C} 2$ posterior arthrodesis techniques. Spine. 2007;32(13):E363-E370.

29. Reilly TM, Sasso RC, Hall PV. Atlantoaxial stabilization: clinical comparison of posterior cervical wiring technique with transarticular screw fixation. J Spinal Disord Tech. 2003;16(3):248-253.

30. Paramore CG, Dickman CA, Sonntag VK. The anatomical suitability of the $\mathrm{C} 1-2$ complex for transarticular screw fixation. J Neurosurg. 1996;85(2):221-224.

31. Harms J, Melcher RP. Posterior C1-C2 fusion with polyaxial screw and rod fixation. Spine. 2001;26(22):2467-2471.

Disclosures and COI: Isaac Moss is a consultant and receives personal fees for Stryker (Kalamazoo, MI), Nuvasive (San Diego, CA), Spineart USA (Irvine, CA), and Pfizer Inc. (New York, NY).

Corresponding Author: Cameron Kia, MD, University of Connecticut Health Center, 263 Farmington Ave, Farmington, CT 06032. Phone: (781) 504-6294; Email: ckia@uchc.edu.

Published 28 August 2020

This manuscript is generously published free of charge by ISASS, the International Society for the Advancement of Spine Surgery. Copyright @ 2020 ISASS. To see more or order reprints or permissions, see http://ijssurgery.com. 